\title{
(-)-7-Hydroxycassine: a New 2,6-Dialkylpiperidin-3-ol Alkaloid and other Constituents Isolated from Flowers and Fruits of Senna spectabilis (Fabaceae)
}

\author{
Cláudio Viegas Junior, ${ }^{*}, a$ Marcos Pivatto, ${ }^{b}$ Amanda de Rezende, ${ }^{c}$ Lidilhone Hamerski, ${ }^{c}$ \\ Dulce Helena Siqueira Silva ${ }^{c}$ and Vanderlan da Silva Bolzani ${ }^{*, c}$
}

${ }^{a}$ Phytochemistry and Medicinal Chemistry Laboratory (LFQM), Institute of Chemistry, Federal University of Alfenas, 37130-000 Alfenas-MG, Brazil

${ }^{b}$ Institute of Chemistry, Federal University of Uberlâdia, 38400-902 Uberlândia-MG, Brazil

${ }^{c}$ Nucleus for Bioassays, Biosynthesis and Ecophysiology of Natural Products (NuBBE), Organic Chemistry Department, Institute of Chemistry, São Paulo State University (UNESP) 'Júlio de Mesquita Filho', CP 355, 14801-970 Araraquara-SP, Brazil

\begin{abstract}
O estudo fitoquímico das flores e frutos verdes de Senna spectabilis forneceu um novo alcaloide 2,6-dialquilpiperidin-3-ol chamado de (-)-7-hidróxi-cassina, juntamente com cinco alcaloides conhecidos: (-)-cassina, (-)-espectalina, (-)-3-O-acetil-espectalina, (-)-7-hidróxi-espectalina e (-)-6-iso-espectalina. Além dos alcaloides, também foram isolados constituintes químicos de outras classes como o esteroide $\beta$-sitosterol, os flavonoides luteolina e 3-metóxi-luteolina, o triterpeno ácido betulínico e o ácido trans-cinâmico. A partir do levantamento bibliográfico foi possível observar que os compostos estão sendo relatados pela primeira vez nesta espécie.
\end{abstract}

The phytochemical study of flowers and green fruits of Senna spectabilis furnished a new substituted 2,6-dialkylpiperidin-3-ol alkaloid, named (-)-7-hydroxycassine, along with five known piperidine alkaloids: (-)-cassine, (-)-spectaline, (-)-3-O-acetylspectaline, (-)-7-hydroxyspectaline and (-)-iso-6-spectaline. In addition to non-alkaloidal, chemical constituents from other chemical classes were also identified, including the steroid $\beta$-sitosterol, the flavonoids luteolin and 3-methoxyluteolin, the triterpene betulinic acid and trans-cinnamic acid. To our knowledge, compounds are being reported for the first time in this species.

Keywords: Senna spectabilis, (-)-7-hydroxycassine, piperidine alkaloids

\section{Introduction}

Senna and Cassia are considered the two most representative genera of the Fabaceae family, with some species used in folk medicine. The placement of these genera in the family has always been controversial, and in the new classification of Fabaceae, several species of Cassia were included in the genus Senna due to being morphologically similar. ${ }^{1}$ These species are known to biosynthesize flavonoids, anthraquinones, stilbenes and alkaloids. Many of these substances have been described for their biological and pharmacological properties, which include antibacterial, laxative, anti-ulcerogenic, cytotoxic,

*e-mail: viegas@unifal-mg.edu.br, cvjviegas@gmail.com, bolzaniv@iq.unesp.br antifungal, analgesic, antiinflammatory, antioxidant and hepatoprotective qualities. ${ }^{2}$

Data from the literature, published in the 1960s and 1970s, describe some species of Senna and Cassia, including C. carnaval, ${ }^{3}$ C. excelsa,${ }^{4}$ S. spectabili ${ }^{5}$ and C. leptophylla,${ }^{6}$ as sources of piperidine alkaloids of long chain 2,6-dialkylpiperidin-3-ol, which are rare in nature. ${ }^{7}$ Recently, a series of new long chain alkaloids 2,6-dialkylpyridin-3-ol was isolated from the leaves of S. multijuga, demonstrating the diversity of these compounds in the genus Senna. These metabolites may be important chemical markers in the validation of the new taxonomy that includes several examples of Cassia in Senna. ${ }^{8}$

Senna spectabilis is a tree used in urbanization and occurs from Minas Gerais to Rio Grande do Sul States., ${ }^{910}$ The species is used in folk medicine for the treatment of constipation, insomnia, anxiety, epilepsy, malaria, 
dysentery and cephalalgia. ${ }^{9,11}$ Pharmacological studies have shown some of the following activity: sedative and anticonvulsant, antimalarial ${ }^{9,11}$ and antimicrobial ${ }^{12}$ cytotoxicity ${ }^{13}$ from studies of various organs of S. spectabilis. Góngora et al..$^{14}$ demonstrated that the alkaloidic extract obtained from the bark of this plant acts on central nervous system. ${ }^{14}$ In another study, Sriphong et al. ${ }^{13}$ isolated several alkaloids from flowers of $S$. spectabilis, among them, a new 3(R)-benzoyloxy-2(R)-methyl$6(R)$-(11'-oxododecyl)-piperidine, and reported toxic and cytotoxicity activities of the metabolites. For more than two decades, researchers at the Nucleus for Bioassays, Biosynthesis and Ecophysiology of Natural Products (NuBBE, UNESP, Araraquara-SP, Brazil) have been investigating $S$. spectabilis from a chemical and biological standpoint, and this has resulted in the isolation of several bioactive alkaloids of the type 2,6-dialkylpiperidin-3-ol. , $, 8,15-18^{-18}$ In the leaves of S. spectabilis var. excels, Silva et al. ${ }^{19}$ first reported the isolation of eight pentacyclic triterpenes, as well as caffeine and steroids stigmasterol and $\beta$-sitosterol.

Chemical studies of the flowers and fruits of S. spectabilis led to the isolation of a new alkaloid 2,6-dialkylpiperidin3-ol (1), as well as another five metabolites from distinct chemical classes, which, although well known, are being reported for the first time in this plant.

\section{Experimental}

Instrumentation and chromatographic material

The uni- and bi-dimensional experiments of ${ }^{1} \mathrm{H}$ and ${ }^{13} \mathrm{C}$ nuclear magnetic resonance (NMR), were obtained using the following spectrometers: Bruker AC-F 200 (operating at $200 \mathrm{MHz}$ for ${ }^{1} \mathrm{H}$ and $50 \mathrm{MHz}$ for ${ }^{13} \mathrm{C}$ ), a Varian Inova 500 (operating at $500 \mathrm{MHz}$ for ${ }^{1} \mathrm{H}$ and $125 \mathrm{MHz}$ for ${ }^{13} \mathrm{C}$ ) using tetramethylsilane (TMS) as internal standard. The absorption spectra in the region of infrared (FTIR) were recorded on a FTIR spectrometer (Nicolet-Impact 400 coupled to a microcomputer provided with Omnic 1.20 software) using $\mathrm{KBr}$ pellets for solids and films for oily substances. The high resolution mass spectra with electrospray ionization (HRESIMS) were measured on an ultrOTOF (Bruker $_{\mathrm{Q}}$ Daltonics) spectrometer, operating in the positive mode and using $\mathrm{MeOH} / \mathrm{H}_{2} \mathrm{O}(4: 1)$ as solvent system. Melting points were determined on a digital device, made by the Microquímica products, model number MQAPF-301 and are uncorrected. Optical rotations were measured on a Perkin Elmer model 341 polarimeter equipped with a sodium lamp $(\lambda=589 \mathrm{~nm})$ at $20{ }^{\circ} \mathrm{C}$ using $\mathrm{CH}_{2} \mathrm{Cl}_{2}$ as a solvent.

In chromatographic separations, trademarks Acros silica gel (70-230 mesh) and Sigma neutral alumina (70-290 mesh) were used for gravitational chromatography, and for pressurized separations, Silica gel (230-400 mesh) was used. For separations using chromatography for molecular exclusion, Sephadex LH-20 was used. The comparative thin layer chromatography (TLC) was performed with 60 silica gel (Ø 5-40 $\mu \mathrm{m}$, Merck) and neutral alumina gel ( 5-40 $\mu \mathrm{m}$, Aldrich) with fluorescence indicator in the range of $254 \mathrm{~nm}\left(\mathrm{~F}_{254}\right)$. The substances were revealed in cubes saturated with iodine vapour, in a vanillin/ $\mathrm{H}_{2} \mathrm{SO}_{4}$ solution, iodochloroplatinate or Dragendorff reagent, prepared as described in the literature. ${ }^{20}$ Analytical HPLC (high performance liquid chromatography) separations were performed on a Varian ProStar system equipped with model 410 ternary pump, controlled by the Star Chromatography Workstation program version 5.52, a photodiode detector model 330, a model 410 autosampler and Luna Phenomenex ${ }^{\circledast}$ C-18 $(250 \times 4.6 \mathrm{~mm}, 5 \mu \mathrm{m})$ column; in the preparative HPLC separations, a Varian PrepStar system was utilized, equipped with UV-Vis detector model 320, a model SD-1 binary pump with manual sampler, controlled by the Star Chromatography Workstation program version 5.51 and a corresponding preparative column Luna Phenomenex ${ }^{\circledR} \mathrm{C}-18$ $(250 \times 21.2 \mathrm{~mm}, 5 \mu \mathrm{m})$. The chromatographic analyses were performed with HPLC grade solvents (JT Baker, Mexico) and purified water in a MilliQ plus system (Millipore).

\section{Plant material}

The flowers and green fruits of $S$. spectabilis were collected in Araraquara and Ribeirão Preto cities (São Paulo State, Brazil) in December 2005 and identified by Dr. Inês Cordeiro from Instituto de Botânica in São Paulo-SP, Brazil. A voucher specimen (SP 370 917) is maintained in the herbarium of this institute.

\section{Extraction and isolation}

The flowers and buds ( $3.4 \mathrm{~kg}$ ) of S. spectabilis were dried, powdered and macerated in EtOH for seven days, resulting in $39.7 \mathrm{~g}$ of crude extract (EB-FL). EB-FL was redissolved in $\mathrm{MeOH} / \mathrm{H}_{2} \mathrm{O}$ (4:1) and partitioned with $n$-hexane, AcOEt, $\mathrm{CH}_{2} \mathrm{Cl}_{2}$ and $n$-BuOH, resulting in $n$-hexane (EFL-Hex, $2.0 \mathrm{~g}$ ), ethyl acetate (EFL-Ac, $0.34 \mathrm{~g}$ ), dichloromethane (EFL-Dic, $7.9 \mathrm{~g}$ ) and $n$-butanol (EFL-But, $2.5 \mathrm{~g}$ ) fractions. Analysis by TLC, using iodochloroplatinate and Dragendorf revealed that EFL-Dic contained a greater diversity of alkaloid constituents. Following acid-base extraction, a mixture of alkaloids was obtained and subjected to fractionation by gravitational column chromatography on neutral alumina, eluted with a $\mathrm{CHCl}_{3} / \mathrm{EtOH} / n$-hexane mixture through gradient elution, supplying $151 \mathrm{mg}$ of (-)-3-O-acetylspectaline, a $4.82 \mathrm{~g}$ 
mixture of (-)-cassine and (-)-spectaline and $270 \mathrm{mg}$ of a more polar mixture containing three other alkaloids. This mixture was subjected to preparative TLC on alumina gel, eluted with $\mathrm{CHCl}_{3} / \mathrm{EtOH} / n$-hexane, leading to the isolation of $5.5 \mathrm{mg}$ of (-)-7-hydroxyspectaline, $20 \mathrm{mg}$ of (-)-iso-6-spectaline, and $11 \mathrm{mg}$ of (-)-7-hydroxycassine (1) obtained as a yellow-coloured oil. The chromatographic treatment of EFL-Hex resulted in the isolation of $\beta$-sitosterol (2). ${ }^{19,21}$ The EFL-Ac fraction initially subjected to acid-base extraction, resulted in $240 \mathrm{mg}$ of a non-alkaloidal fraction whose fractionation in a Sephadex ${ }^{\circledR}$ LH-20 column, eluted with $\mathrm{MeOH}$, provided 12 sub-fractions of $25 \mathrm{~mL}$ each. A preliminary analysis with ${ }^{1} \mathrm{H}$ NMR led to the selection of the sub-fraction 6 , which following purification in a chromatographic column on silica gel resulted in a yellow solid, which decomposed above $320{ }^{\circ} \mathrm{C}$, ${ }^{22}$ identified as luteolin (3). ${ }^{23}$

The green fruits $(3 \mathrm{~kg}$ ) of $S$. spectabilis were powdered and macerated in EtOH for five days, providing $13.1 \mathrm{~g}$ of crude extract (EB-FR). EB-FR was reconstituted in $\mathrm{MeOH} / \mathrm{H}_{2} \mathrm{O}(4: 1)$ and partitioned with $n$-hexano, $\mathrm{CH}_{2} \mathrm{Cl}_{2}$, AcOEt and $n$-BuOH, generating four fractions: EFR-Hex (0.29 g), EFR-Dic (0.87 g) EFR-Ac (1.15 g) and EFR-Bu (1.96 g), respectively. A preliminary analysis by TLC and ${ }^{1} \mathrm{H}$ NMR, led to the selection of fractions EFR-Dic and EFR-Bu for chemical study. The chromatographic treatment EFR-Dic, resulted in 150 sub-fractions of $10 \mathrm{~mL}$ each, regrouped into 13 new sub- fractions. The sub-fraction 42-44 (504 $\mathrm{mg}$ ) was subjected to TLC, providing $20 \mathrm{mg}$ of betulinic acid (5) (Figure 1). ${ }^{24}$ The sub-fraction 51-58 (248 mg) was subjected to column chromatographic (CC) on silica gel, eluted under reduced pressure with binary mixtures of EtOAc/Hex and EtOAc/ $\mathrm{MeOH}$, providing $78 \mathrm{sub}$-fractions of $10 \mathrm{~mL}$ each, grouped according to similarity into 17 new sub-fractions. The subfraction 1-10 (42 mg) was purified by preparative HPLC, resulting in four new sub-fractions. The sub-fractions with retention times $\left(t_{\mathrm{R}}\right)$ of 23.2 and $27.6 \mathrm{~min}$ were analysed by ${ }^{1} \mathrm{H}$ and ${ }^{13} \mathrm{C} 1 \mathrm{D}$ and $2 \mathrm{D}$ NMR and compared with literature data, ${ }^{21}$ leading to the identification of luteolin (3) $\left(7.7 \mathrm{mg}, t_{\mathrm{R}}=23.2 \mathrm{~min}\right.$ ) of 3-methoxyluteolin (4) $\left(8.4 \mathrm{mg}, t_{\mathrm{R}}=27.6 \mathrm{~min}\right)$. The fractionation of EFR-Bu in a reverse phase column $\mathrm{C}$-18, eluted in gradient of $\mathrm{H}_{2} \mathrm{O} / \mathrm{MeOH}$, resulted in 8 sub-fractions of $500 \mathrm{~mL}$ each. The chromatographic fractionation of sub-fraction 4 (886 mg) in molecular exclusion column Sephadex ${ }^{\circledR}$ LH-20, eluted with $\mathrm{MeOH}$, resulted in the isolation of a white solid, melting range of $130-133{ }^{\circ} \mathrm{C}$, was identified as trans-cinnamic acid (6). ${ }^{22}$

\section{4 (-)-7-Hydroxycassine (1)}

FTIR (KBr pellet) $v_{\max } / \mathrm{cm}^{-1} 3350,2928,2856,1711$, 1632, 1452, 1362, 1166, 1072, 758; HRESIMS m/z $314.2689[\mathrm{M}+\mathrm{H}]^{+}$(calcd. for $\mathrm{C}_{18} \mathrm{H}_{36} \mathrm{NO}_{3}, 314.2690$ ); $[\alpha]_{\mathrm{D}}^{20}-27\left(c 0.028, \mathrm{CH}_{2} \mathrm{Cl}_{2}\right) ;{ }^{1} \mathrm{H}$ and ${ }^{13} \mathrm{C}$ 1D and 2D NMR (Table 1).

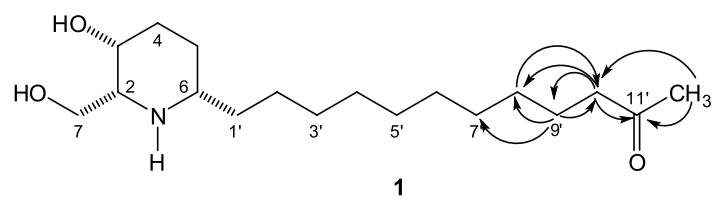

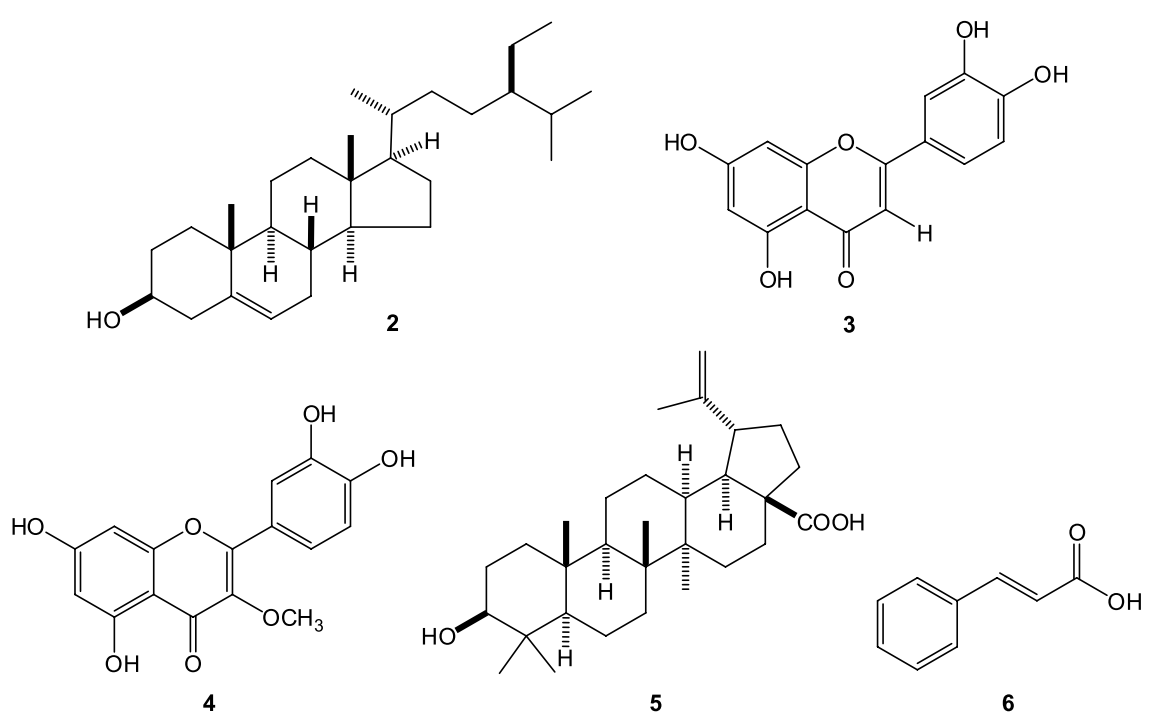

Figure 1. Compounds isolated from flowers and unripe fruits of $S$. spectabilis and correlations ${ }^{1} \mathrm{H} \rightarrow{ }^{13} \mathrm{C}$ observed in the HMBC contour map of $\mathbf{1}$. 
Table 1. NMR data for compound 1 at $500\left({ }^{1} \mathrm{H}\right)$ and $125\left({ }^{13} \mathrm{C}\right) \mathrm{MHz}$, in $\mathrm{CDCl}_{3}$

\begin{tabular}{|c|c|c|c|}
\hline Position & $\delta_{\mathrm{H}}{ }^{\mathrm{a}}($ mult., $J / \mathrm{Hz})$ & COSY & $\delta_{\mathrm{C}}{ }^{\mathrm{a}}$ \\
\hline 2 & $3.00(\mathrm{~m})$ & H-3, H-7 & $58.59(\mathrm{CH})$ \\
\hline 3 & $3.62(\mathrm{~m})$ & $\mathrm{H}-2$ & $66.22(\mathrm{CH})$ \\
\hline $4_{\text {eq }}$ & $1.91(\mathrm{~m})$ & & $27.72^{\mathrm{b}}\left(\mathrm{CH}_{2}\right)$ \\
\hline $4_{\mathrm{ax}}$ & $1.75-1.66(\mathrm{~m})$ & $\mathrm{H}-5_{\mathrm{eq}}, \mathrm{H}-5_{\mathrm{ax}}$ & \\
\hline $5_{\text {eq }}$ & $1.61(\mathrm{~m})$ & $\mathrm{H}-6, \mathrm{H}-4_{\mathrm{ax}}$ & $25.78\left(\mathrm{CH}_{2}\right)$ \\
\hline $5_{\mathrm{ax}}$ & $1.44-1.38(\mathrm{~m})$ & H-6 & \\
\hline 6 & $2.90(\mathrm{~m})$ & $\mathrm{H}-1^{\prime}, \mathrm{H}-5_{\mathrm{eq}}$ & $50.48(\mathrm{CH})$ \\
\hline $7 \mathrm{a}$ & $3.73(\mathrm{dd}, 11.5 ; 7.5)$ & $\mathrm{H}-2$ & $60.47\left(\mathrm{CH}_{2}\right)$ \\
\hline $7 b$ & $3.64(\mathrm{dd}, 11.5 ; 7.5)$ & & \\
\hline $1^{\prime}$ & $1.44-1.38(\mathrm{~m})$ & H-6 & $32.68^{\mathrm{b}}\left(\mathrm{CH}_{2}\right)$ \\
\hline $2^{\prime}$ & $1.20(\mathrm{~m})$ & H-1', H-3' & $26.05\left(\mathrm{CH}_{2}\right)$ \\
\hline $3^{\prime}$ & $1.20(\mathrm{~m})$ & H-2', H-4' & $29.48^{\mathrm{b}}\left(\mathrm{CH}_{2}\right)$ \\
\hline $4^{\prime}$ & $1.20(\mathrm{~m})$ & H-3, H-5' & $29.44^{\mathrm{b}}\left(\mathrm{CH}_{2}\right)$ \\
\hline 5 & $1.20(\mathrm{~m})$ & H-4', H-6' & $29.43^{\mathrm{b}}\left(\mathrm{CH}_{2}\right)$ \\
\hline 6 & $1.20(\mathrm{~m})$ & H-5, H-7' & $29.36^{\mathrm{b}}\left(\mathrm{CH}_{2}\right)$ \\
\hline $7^{\prime}$ & $1.20(\mathrm{~m})$ & H-6', H-8' & $29.33^{\mathrm{b}}\left(\mathrm{CH}_{2}\right)$ \\
\hline $8^{\prime}$ & $1.20(\mathrm{~m})$ & H-7', H-9' & $29.13^{\mathrm{b}}\left(\mathrm{CH}_{2}\right)$ \\
\hline $9^{\prime}$ & $1.51(\mathrm{~m})$ & H-10' & $23.84\left(\mathrm{CH}_{2}\right)$ \\
\hline $10^{\prime}$ & $2.34(\mathrm{t}, 7.5)$ & H-8, H-9', & $43.79\left(\mathrm{CH}_{2}\right)$ \\
\hline $11^{\prime}$ & & & $209.63(\mathrm{C})$ \\
\hline $12^{\prime}$ & $2.06(\mathrm{~s})$ & & $29.82\left(\mathrm{CH}_{3}\right)$ \\
\hline
\end{tabular}

${ }^{\mathrm{a}}$ Chemical shifts $(\delta)$ in ppm, relative to TMS as internal standard $\left(\delta_{\mathrm{TMS}}=0.00\right) .{ }^{\mathrm{b}}$ The assignments were based on calculated $\delta_{\mathrm{C}}($ ChemDraw Ultra 10.0) and may be interchanged in the column.

\section{Results and Discussion}

The liquid-liquid partition of the ethanol extracts of flowers (EFL) and green fruits (EFR) of S. spectabilis, successively with $n$-hexane, dichloromethane, ethyl acetate and $n$-butanol fractions resulted in EFL-Hex and EFR-Hex, EFL-Dic and EFR-Dic, EFL-Ac and EFR-Ac, EFL-Bu and EFR-Bu, EFL-HA and EFR-HA, respectively. The analysis by comparative TLC revealed the presence of several chemical classes, with predominant alkaloid fractions in EFL-Dic, EFR-Dic, EFL-Ac and EFR-Ac. The chromatographic treatment of EFL-Hex and EFL-Ac led to the isolation of $\beta$-sitosterol ${ }^{19,21}$ (2) and $\operatorname{luteolin}^{23}(\mathbf{3})$ (Figure 1), respectively, being reported for the first time in this plant. In view of finding alkaloids in the EFL-Dic fraction, acid-base extraction was carried out and supplied a mixture of alkaloids, the chromatographic fractionation that resulted in the reisolation of $(-)$-cassine, $(-)$-spectaline, $(-)-3-O$-acetylspectaline, (-)-7-hydroxyspectaline and (-)-iso-6-spectaline. ${ }^{15,17}$ In addition to these five substances, a new alkaloid (1) was isolated, and the ${ }^{1} \mathrm{H}$ and ${ }^{13} \mathrm{C}$ NMR data showed different chemical shifts distinct from other metabolites despite displaying the same structural pattern of a 2,3,6-trisubstituted piperidine system. The HRESIMS spectrum of compound $\mathbf{1}$ provided the molecular ion peak at $\mathrm{m} / z 314.2689[\mathrm{M}+\mathrm{H}]^{+}$(calcd. for $\mathrm{C}_{18} \mathrm{H}_{36} \mathrm{NO}_{3}, 314.2690$ ), compatible with molecular formula $\mathrm{C}_{18} \mathrm{H}_{35} \mathrm{NO}_{3}$, with two hydrogen deficiency index. In the analysis of sequential mass spectra (ESI-MS-MS), neutral elimination of two consecutive molecules of $\mathrm{H}_{2} \mathrm{O}$ was observed, consistent with the proposed structure of alkaloid $\mathbf{1}$ (Figures S1 and S2 in the Supplementary Information (SI) section). The analysis of the ${ }^{1} \mathrm{H}$ and ${ }^{13} \mathrm{C}$ NMR spectra (Table 1) and mass spectra suggested that substance $\mathbf{1}$ had structural pattern similar to others previously isolated, ${ }^{17}$ particularly with the (-)-7-hydroxyspectaline, a natural homologue previously isolated from flowers of S. spectabilis. ${ }^{15}$ From the analysis of ${ }^{1} \mathrm{H}$ NMR spectra of $\mathbf{1}$, it was possible to observe a broad singlet at $\delta 1.20\left(14 \mathrm{H}, \mathrm{H}-2^{\prime}-\mathrm{H}^{-} 8^{\prime}\right)$, a singlet at $\delta 2.06(3 \mathrm{H}$, H-12'), a triplet at $\delta 2.34\left(2 \mathrm{H}, \mathrm{H}-10^{\prime}\right)$, two multiplets at $\delta 3.00(1 \mathrm{H}, \mathrm{H}-2)$ and $2.90(1 \mathrm{H}, \mathrm{H}-6)$, a multiplet at $\delta 3.62$ $(1 \mathrm{H}, \mathrm{H}-3)$ and two double doublets at $\delta 3.64(1 \mathrm{H})$ and $3.73(1 \mathrm{H})$, referring to the geminal hydrogens $\mathrm{H}-7$, which correlated in the HMQC (heteronuclear multiple-quantum correlation) spectrum with a methylene carbon signal at $\delta$ 60.47. The HMQC spectrum also showed correlations between $\mathrm{H}-2, \mathrm{H}-3, \mathrm{H}-6$ with the signals of the carbons at $\delta 58.59,66.22$ and 50.48, respectively. Furthermore, in the ${ }^{1} \mathrm{H}$ NMR spectrum, two multiplets at $\delta$ 1.44-1.38 $(2 \mathrm{H})$ and $1.51(2 \mathrm{H})$ were observed and show correlations in the HMQC spectrum with the signals of the methylene carbons at $\delta 32.68\left(\mathrm{C}-1^{\prime}\right)$ and $23.84\left(\mathrm{C}-9^{\prime}\right)$, respectively. In the HMBC (heteronuclear multiple bond correlation) spectra, correlations were observed between the triplet at $\delta 2.34\left(\mathrm{H}-10^{\prime}\right)$, the singlet at $\delta 2.06\left(3 \mathrm{H}, \mathrm{H}-12^{\prime}\right)$, with the signal of the carbonyl carbon at $\delta 209.63$ (C-11'), which shows the same substitution pattern at the end of the decamethylene-methyl-ketone side chain common to the piperidine alkaloids isolated from $S$. spectabilis. The assignment of other signals is described in Table 1 and the main correlations observed in the HMBC contour map are in Figure 1. The stereochemistries of the carbons C-2, C-3 and C-6 of 1, have been proposed based on the structural similarity between the chemical shifts observed in ${ }^{1} \mathrm{H}$ and ${ }^{13} \mathrm{C}$ NMR spectra when compared with those of (-)-7-hydroxyspectaline isolated from S. spectabilis. ${ }^{15}$ The polarimetric analysis $\left([\alpha]_{D}^{20}=-27\right)$ of $\mathbf{1}$ was another important detail in confirming absolute stereochemistry, as it was the same as its homologue (-)-7-hydroxyspectaline. Another feature that proves the proposed stereochemistry for the derivative is its biogenesis since both $\mathbf{1}$ and 
(-)-7-hydroxyspectaline may be derived biosynthetically from the precursors (-)-cassine and (-)-spectaline by a subsequent oxidation of the methyl group at C-7. Taking into consideration that the oxidation reaction at $\mathrm{C}-7$ does not involve steps that allow for the inversion of the configuration of the stereogenic centres (C-2, C-3 and C-6), these remain unchanged, being $R, R$ and $S$, respectively. ${ }^{15}$ Thus, based on NMR data compared with that of the alkaloids (-)-cassine and (-)-spectaline and especially with that of (-)-7-hydroxyespectaline, the structure $(2 R, 3 R, 6 S)$ 2-hydroxymethyl-6-(11'-dodecyl-one)-piperidin-3-ol was proposed for $\mathbf{1}$, denominated (-)-7-hydroxycassine, as being a homologue of (-)-7-hydroxyspectaline (Figure 1), described for the first time in the literature.

The chromatographic fractionation of EFR-Dic again led to the identification of alkaloids (-)-cassine, $(-)$-spectaline, (-)-3-O-acetylspectaline and a mixture of metabolites not reactive with Dragendorff and iodochloroplatinate reagents. A new chromatographic treatment in column of this mixture resulted in the isolation of two flavonoids, identified as luteolin (3) and 3-methoxyluteolin (4) ${ }^{23}$ and a triterpene, identified as betulinic acid $(\mathbf{5})^{24}$ (Figure 1), all first described for the first time in $S$. spectabilis. The $n$-butanol fraction of the fruits extract (EFR-Bu) was subjected to chromatographic fractionation on a reversed phase column, which resulted in the isolation and identification of trans-cinnamic acid (6) (Figure 1), also described for the first time in this species.

\section{Conclusions}

Senna spectabilis proved to be an important source of rare piperidine alkaloids, which can be used as probes for drug design and other secondary metabolites. The phytochemical study of flowers and green fruits of S. spectabilis has furnished a new 2,6-dialkylpiperidin-3-ol alkaloid, named (-)-7-hydroxycassine (1), along with five known piperidine alkaloids, (-)-cassine, (-)-spectaline, (-)-3-O-acetylspectaline, (-)-7-hydroxyspectaline and (-)-iso-6-spectaline. Furthermore, non-alkaloidal chemical constituents from other chemical classes were also identified, including the steroid $\beta$-sitosterol (2), the flavonoids luteolin (3) and 3-methoxyluteolin (4), the triterpene betulinic acid (5) and trans-cinnamic acid (6). To our knowledge, compounds 1-6 are reported for the first time in this species.

\section{Supplementary Information}

Supplementary information (Figures S1-S11) is available free of charge at http://jbcs.sbq.org.br as PDF file.

\section{Acknowledgements}

This work was supported by grants from the State of São Paulo Research Foundation (FAPESP) as part of Biota-FAPESP, The Biodiversity Virtual Institute Program (www.biotasp.org.br), grant No. 03/02176-7, awarded to V. S. B., principal investigator. The researchers also acknowledge FAPESP, CAPES and CNPq for fellowships. The authors thank PhD Norberto Peporine Lopes (FCFRP-USP in Ribeirão Preto-SP, Brazil) for mass spectra and to PhD Eduardo Rolim de Oliveira (IQ-UFRGS in Porto Alegre-RS, Brazil) for polarimetric measurements.

\section{References}

1. Rodrigues, R. S.; Flores, A. S.; Miotto, T. S.; Baptista, L. R. M.; Acta Bot. Bras. 2005, 19, 1.

2. Samy, R. P.; Ignacimuthu, S.; Sen, A.; J. Ethnopharmacol. 1998, 62, 173; Agarkar, S. V.; Jadge, D. R.; Asian J. Chem. 1999, 11, 295; Samy, R. P.; Ignacimuthu, S.; J. Ethnopharmacol. 2000, 69, 63; Bhakta, T.; Mukherjee, P. K.; Mukherjee, K.; Banerjee, S.; Mandall, S. C.; Maity, T. K.; Pal, M.; Saha, B. P.; J. Ethnopharmacol. 1999, 66, 277; Tona, L.; Ngimbi, N. P.; Tsakala, M.; Mesia, K.; Cimanga, K.; Apers, S.; Bruyne, T. D.; Pieters, L.; Totté, J.; Vlietrick, A. J.; J. Ethnopharmacol. 1999, 68, 193; Jafri, M. A.; Subhami, M. J.; Javed, K.; Singh, S.; J. Ethnopharmacol. 1999, 66, 355; Jain, S. C.; Jain, R.; Sharma, R. A.; Capasso, F.; J. Ethnopharmacol. 1997, 58, 135; Akah, P. A.; Orisakwe, O. E.; Gamaniel, K. S.; Shittu, A.; J. Ethnopharmacol. 1998, 62, 123; Ibraim, D.; Osman, H.; J. Ethnopharmacol. 1995, 45, 151; Mascolo, N.; Capasso, R.; Capasso, F.; Phytoter. Res. 1998, 12, S143.

3. Lythgoe, D.; Vernengo, M. J.; Tetrahedron Lett. 1967, 12, 1133.

4. Highet, R. J.; J. Org. Chem. 1964, 29, 471; Rice Jr., W. Y.; Coke, J. L.; J. Org. Chem. 1966, 31, 1010.

5. Christofidis, I.; Welter, A.; Jadot, J.; Tetrahedron 1977, 33, 977; Christofidis, I.; Welter, A.; Jadot, J.; Tetrahedron 1977, 33, 3005.

6. Bolzani, V. S.; Gunatilaka, A. A. L.; Kingston, D. G. I.; Tetrahedron 1995, 51, 5929.

7. Viegas Jr., C.; Rezende, A.; Silva, D. H. S.; Castro-Gamboa, I.; Bolzani, V.S.; Barreiro, E. J.; Miranda,A.L.P.; Alexandre-Moreira, M. S.; Young, M. C. M.; Quím. Nova 2006, 29, 1279.

8. Serrano, M. A. R.; Pivatto, M.; Francisco, W.; Danuello, A.; Regasini, L. O.; Lopes, E. M. C.; Lopes, M. N.; Young, M. C. M.; Bolzani, V. S.; J. Nat. Prod. 2010, 73, 482; Francisco, W.; Pivatto, M.; Danuello, A.; Regasini, L. O.; Baccini, L. R.; Young, M. C. M.; Lopes, N. P.; Lopes, J. L. C.; Bolzani, V. S.; J. Nat. Prod. 2012, 75, 408.

9. Bum, E. N.; Nkantchoua, G. N.; Njikam, N.; Taiwe, G. S.; Ngoupaye, G. T.; Pelanken, M. M.; Nanga; Maidawa, F.; 
Rakotonirina, A.; Rakotonirina, S. V.; Int. J. Pharmacol. 2010 6,123 .

10. Lorenzi, H.; Árvores Brasileiras: Manual de Identificacão e Cultivo de Plantas Arbóreas do Brasil; Plantarum: Nova Odessa, Brasil, 1998.

11. Nsonde-Ntandou, G. F.; Ndounga, M.; Ouamba, J. M.; Gbeasso, M.; Etou-Ossebi, A.; Ntoumi, F.; Abena, A. A.; Phytotherapie 2005, 1, 13.

12. Chukeatirote, E.; Hanpattanakit, P.; Kaprom, A.; Tovaranonte, J.; J. Plant Sci. 2007, 2, 123; Krishnan, N.; Ramanathan, S.; Sasidharan, S.; Murugaiyah, V.; Mansor, S. M.; Int. J. Pharmacol. 2010, 6, 506.

13. Sriphong, L.; Sotanaphun, U.; Limsirichaikul, S.; Wetwitayaklung, P.; Chaichantipyuth, C.; Pummangura, S.; Planta Med. 2003, 69, 1054.

14. Góngora, B. M.; Alvarez, J. C.; Pinzón, R.; Olarte, J.; Ospina, L. F.; Bautista, S.; Pedraza, M. T.; Puentes, L. J.; Rev. Colomb. Cienc. Quim. Farm. 1996, 25, 7.

15. Viegas Jr., C. Bolzani, V. S.; Furlan, M.; Barreiro, E. J.; Young, M. C. M.; Tomazela, D.; Eberlin, M. N.; J. Nat. Prod. 2004, 67, 908.

16. Viegas, Jr., C.; Silva, D. H. S.; Pivatto, M.; de Rezende, A.; Castro-Gamboa, I.; Bolzani, V. S.; Nair, M. G.; J. Nat. Prod. 2007, 70, 2026.

17. Pivatto, M.; Crotti, A. E. M.; Lopes, N. P.; Castro-Gamboa, I.; de Rezende, A.; Viegas Jr., C.; Young, M. C. M.; Furlan, M.; Bolzani, V. S.; J. Braz. Chem. Soc. 2005, 16, 1431.
18. Viegas Jr., C.; Bolzani, V. S.; Pimentel, L. S. B.; Castro, N. G.; Cabral, R. F.; Costa, R. S.; Floyd, C.; Rocha, M. S.; Young, M. C. M.; Barreiro, E. J.; Fraga, C. A. M.; Bioorg. Med. Chem. 2005, 13, 4184.

19. Silva, F. O.; Oliveira, I. R.; Silva, M. G. V.; Braz-Filho, R.; Quim. Nova 2010, 33, 1874.

20. Pateh, U. U.; Haruna, A. K.; Garba, M.; Iliya, I.; Sule, I. M.; Abubakar, M. S.; Ambi, A. A.; Niger. J. Pharm. Sci. 2009, 8, 19; Seo, S.; Uomori, A.; Yoshimura, Y.; Takeda, K.; Seto, H.; Ebizuka, Y.; Noguchi, H.; Sankawa, U.; J. Chem. Soc., Perkin Trans. 1 1988, 8, 2407.

21. Agrawal, P. K.; Carbon-13 NMR of Flavonoids; Elsevier Science Publishing Co. Inc.: New York, NY, USA, 1989.

22. Mahato, S. B.; Kundu, A. P.; Phytochemistry 1994, 37, 1517.

23. Touchstone, J. C.; Dobbins, M. F.; Practice of Thin Layer Chromatography, $2^{\text {nd }}$ ed.; Wiley Interscience: New York, USA, 1978.

24. The Merck Index, $12^{\text {th }}$ ed.; Merck Co. Inc.: Whitehouse Station, NJ, USA, 1996.

Submitted: December 3, 2012

Published online: January 22, 2013

FAPESP has sponsored the publication of this article. 